\title{
Retinal detachment after congenital cataract surgery
}

\author{
J. J. KANSKI, A. R. ELKINGTON, AND R. DANIEL \\ Moorfields Eye Hospital, High Holborn, London, $W C_{\mathrm{I}} V{ }_{7} A \mathcal{N}$
}

Those born with congenital cataracts tend to develop retinal detachments, irrespective of whether or not cataract surgery is undertaken (Malbrán and Dodds, I964), although the patient may reach middle age before the retina separates (Shapland, I962). The prospects of curing such detachments are generally regarded as poor (McDonald, 1957), and since the literature is devoid of any series giving figures, this report presents the results of retinal detachment surgery in 34 eyes of 25 patients who developed retinal detachments subsequent to earlier surgery for congenital cataract.

\section{Patients and methods}

Twenty-five patients who had had congenital cataract operations underwent retinal detachment surgery at the High Holborn branch of Moorfields Eye Hospital between 195 I and 1972. The detachments were bilateral in nine cases; fifteen patients were males and ten females. All but two had had bilateral cataract surgery performed. Of the 34 eyes which developed detachments, retinal breaks could be seen in only nine ("U"-shaped tears in five, round holes in two, a giant tear in one, and a dialysis in one). The average age of the patients at the time of cataract surgery was $6 \cdot 2$ years (Table I). The average interval between cataract surgery and the subsequent development of a detachment in that eye was 33.3 years (Table II).

Table I Age of patients at time of cataract surgery (mean age $6 \cdot 2 \mathrm{yrs}$ )

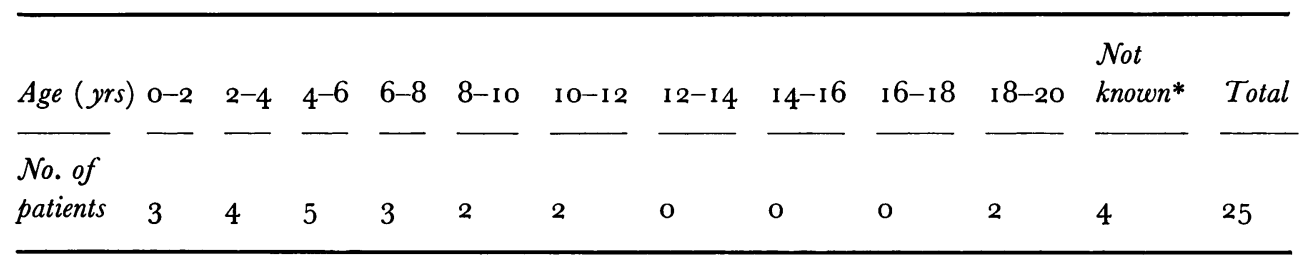

* 4 patients had operations in "childhood" (no specific age was recorded)

Table II Interval between cataract surgery and development of detachment (mean 33.3 yrs)

\begin{tabular}{lllllllllllllll}
$\begin{array}{l}\text { Time } \\
(y r s)\end{array}$ & O-I & I-5 & $5^{-10}$ & I O-I 5 & I 5-20 & $20-25$ & $25-30$ & $30-35$ & $35-40$ & $40-45$ & $45-50$ & $50-55$ & $55-60$ & Total \\
$\begin{array}{l}\text { No. of } \\
\text { eyes }\end{array}$ & I & I & I & 0 & 3 & 4 & 4 & 5 & 3 & 4 & 4 & 3 & I & 34 \\
\hline
\end{tabular}

Received for publication March 23, 1973

Address for reprints: J. J. Kanski, F.R.C.S., as above 


\section{Results}

In eighteen of the 34 eyes treated, the retina remained successfully re-attached after an average follow-up of 6 years (range $3 \mathrm{mths}$ to $2 \mathrm{I} \mathrm{yrs}$ ). Two cases were only partially successful (Tables III, IV, V).

Table III Anatomical results of various detachment operations

\begin{tabular}{|c|c|c|c|c|}
\hline \multirow{2}{*}{ Type of operation } & \multicolumn{4}{|l|}{ Result } \\
\hline & Success & Partial success & Failure & Total \\
\hline Encirclement alone & $10\}$ & I & 6 & 17 \\
\hline Encirclement + subsequent reoperation & $3\}$ & - & I & 4 \\
\hline Local procedures alone & $2\}$ & I & I & 4 \\
\hline $\begin{array}{l}\text { Local procedures + subsequent } \\
\text { reoperation }\end{array}$ & $3\}$ & - & 3 & 6 \\
\hline Inadequate details & o & - & 3 & 3 \\
\hline Total & 18 & 2 & 14 & 34 \\
\hline
\end{tabular}

Table IV Visual acuity in eighteen successful cases

\begin{tabular}{|c|c|c|c|c|c|}
\hline Visual acuity & $6 / 4-6 / 12$ & $6 / 18-6 / 36$ & $6 / 60-3 / 60$ & Counting fingers & Total \\
\hline No. of patients & 7 & 6 & 4 & I & 18 \\
\hline
\end{tabular}

Table V Length of follow-up (yrs) of eighteen successful cases (mean 6 yrs)

\begin{tabular}{|c|c|c|c|c|c|c|c|c|c|}
\hline Length of follow-up (yrs) & $0-I$ & $I-3$ & $3-6$ & $6-9$ & $9^{-12}$ & I 2-I 5 & I $5^{-1} 8$ & I 8-2 I & Total \\
\hline No. of patients & 3 & 2 & 6 & 4 & 0 & I & I & I & 18 \\
\hline
\end{tabular}

Of the 2 I eyes encircled as a primary procedure, the retina was replaced in thirteen, and partially so in another one; surgery failed in seven. Re-operation was necessary in three patients.

Of the ten eyes treated by a local procedure in the first instance, the operation was a success in five, partly successful in one, but failed in four. Re-operation was required in three patients.

Of the nine eyes in which retinal breaks were seen, surgery was successful in five, but failed in four. In the 25 eyes in which no retinal breaks could be seen before surgery, the retina was replaced in thirteen, but remained detached in twelve. Silicone oil was injected into the vitreous of two eyes as a last resort, unfortunately without benefit.

In three cases, since some surgery had been undertaken elsewhere before referral, no adequate operative details were available. 


\section{Discussion}

Falls (1943) pointed out that over 50 per cent. of eyes with congenital cataracts suffer from other defects, such as nystagmus, aniridia, chorio-retinal changes, and strabismus, which seriously impair vision; but inevitably cataract surgery has frequently to be undertaken early in life (Table I).

The long interval before a detachment ensues (average $33.3 \mathrm{yrs}$ : Table II) may be compared with the figure given by Shapland (1962), who reported a lapse of 26 years. Indeed, this delay prompted Schepens (I95I) to question whether the cataract surgery bore sole responsibility for the subsequent detachment; although he did stress the importance of minimizing trauma to the vitreous at the time of cataract surgery. Shapland postulated that myopia and its progressive stretching of the globe, with its manifold complications, was an additional predisposing factor in many cases.

The incidence of retinal detachment after needling of congenital cataract is about Io per cent. (Shapland, I962), and is much higher than the incidence of this complication after extraction for senile cataract ( 2 to 3 per cent.). Most authorities agree with Chandler (I95I) that the more the vitreous is disturbed the greater is the danger of retinal detachment as a late complication; the type of operation relates significantly to the incidence of subsequent detachment. Late detachments occur much more frequently after needling, especially if it is repeated, than after linear extraction.

The success rate of re-attachment ( 50 per cent.) compares unfavourably with the results of detachment surgery in phakic patients, which is usually in the region of 80 per cent. The main reasons for this are $(a)$ the vitreous changes related to the original surgery and (b) the great difficulty in obtaining an adequate view of the retina and in localizing retinal breaks, which are often equatorial or pre-equatorial. The small pupil, together with capsular remnants and frequent corneal disturbance, make ophthalmoscopy difficult and frustrating. The use of the small pupil indirect ophthalmoscope, together with a high-power condensing lens $(+30 \mathrm{D})$, might assist in localizing retinal breaks. Enlarging the pupil by photocoagulation or by the removal of capsular remnants may be required in certain cases; it was necessary in four instances in this series (two capsulectomies, one capsulotomy, and one irido-capsulectomy). In order to avoid these procedures, a broad iridectomy at the time of cataract surgery should be considered in all patients.

Of the 34 eyes treated in this series, retinal breaks could be visualized in only nine. For this reason an equatorial encircling operation was the procedure of choice in $2 \mathrm{I}$ eyes.

It is hoped that, with the advent of more sophisticated methods of treating congenital cataracts (e.g. lens aspiration using the microscope), trauma to the vitreous will be minimized and the incidence of detachments substantially reduced. Until that time, a conservative approach is advocated in patients with bilateral congenital cataracts. If one eye has been operated on successfully and the fundus in the fellow eye can be evaluated and reveals no lesions predisposing to detachment, cataract surgery can be postponed if the visual acuity is better than $6 / 36$ in the phakic eye. If a detachment occurs later in the aphakic eye and retinal detachment surgery is unsuccessful, the fellow eye can then have the cataract removed. It is then reasonable to expect at least one or two decades of sight before a detachment occurs in this eye as well.

\section{Summary}

The results of treating 34 eyes with retinal detachments after congenital cataract surgery are presented. Successful re-attachment of the retina was obtained in 50 per cent. The 
major factors contributing to the poor results were thought to be $(a)$ the inability to visualize the retinal breaks, which were seen in only nine cases, and $(b)$ vitreous changes related to the original surgery. The average interval between cataract surgery and the development of a detachment was 33.3 years.

We are greatly indebted to the Surgeons of Moorfields Eye Hospital, High Holborn Branch, for allowing us to examine the patients under their care.

\section{References}

Ghandler, P. A. (195I) A.M.A. Arch. Ophthal., 45, I 25

FALLS, H. F. (1943) Arch. Ophthal. (Chicago), 29, 210

MCDONALD, P. R. (1957) "Complications of cataract surgery" in "Management of Complications in

Eye Surgery", ed. R. M. Fasanella, p. I 70. Saunders, Philadelphia

MALBRÁN, E., and DODDS, R. (1964) Ophthalmologica (Basel), 147, 343

SCHEPENS, C. L. (195I) A.M.A. Arch. Ophthal., 45, I

ShAPLAND, G. DEE (1962) An. Inst. Barraquer, 3, 420 